\title{
Grazing effects on soil characteristics and vegetation of grassland in northern China
}

\author{
Z. Wang ${ }^{1}$, D. A. Johnson ${ }^{2}$, Y. $\operatorname{Rong}^{1}$, and K. Wang ${ }^{1}$ \\ ${ }^{1}$ Beijing Key Laboratory of Grassland Science, Animal Science and Technology College, China Agricultural University, \\ Beijing 100193, China \\ ${ }^{2}$ USDA-ARS Forage and Range Research Lab, Utah State University, Logan, UT 84322-6300, USA
}

Correspondence to: Y. Rong (rongyuping@cau.edu.cn)

Received: 3 July 2015 - Published in Solid Earth Discuss.: 14 August 2015

Revised: 14 December 2015 - Accepted: 26 December 2015 - Published: 15 January 2016

\begin{abstract}
Large areas of grassland in the agro-pastoral region of northern China were converted into cropland for grain production, and the remaining grasslands are being overgrazed and seriously degraded. The objective of this study was to evaluate how reductions in grazing intensity affect the soil and vegetation characteristics in grasslands of northern China. Soil heterogeneity and vegetation characteristics were evaluated for ungrazed (UG), moderate grazing (MG), and heavy grazing (HG) sites. Grazing increased diversity, but heavy grazing decreased aboveground biomass and increased the non-grass component. The non-grass proportion of total biomass increased with grazing intensity, which was 8, 16 and $48 \%$ for UG, MG and HG sites, respectively. Species richness at the MG and HG sites was significantly higher than at the UG site $(P<0.05)$ with $3.6,5.5$ and 5.7 for UG, MG and HG sites, respectively. Strong spatial dependence of the examined soil properties at $10 \mathrm{~m}$ scale for all grazed sites was revealed by the ratio of nugget to total variation (0-23\%). Overgrazing homogenized soil characteristics at a $10 \mathrm{~m}$ scale. The ranges of spatial autocorrelation for soil organic C (SOC) and total $\mathrm{N}$ were both $>120 \mathrm{~m}$ at the HG site, which was considerably larger than that at the $\mathrm{MG}$ and UG sites with corresponding distances of 17.3 and $20.8 \mathrm{~m}$ for the MG site and 8.6 and $15.0 \mathrm{~m}$ for the UG site, respectively. The sampling density and sampling space for the HG site could be decreased under this scale sampling interval $(10 \mathrm{~m})$. Therefore, MG was recommended as the preferred management alternative for grasslands in northern China because of increased plant diversity without negative consequences related to decreased forage quality, forage quantity and soil
\end{abstract}

heterogeneity for the investigated soil properties in northern China's grasslands.

\section{Introduction}

Arid and semi-arid ecosystems are highly heterogeneous in space and time because of considerable variation in biotic and abiotic factors related to vegetation and soil properties (Schlesinger et al., 1996; Peters et al., 2006; García-Palacios et al., 2011). This heterogeneity is essential to provide multiple ecosystem functions and services such as biodiversity, habitats and ecosystem stability (Peters et al., 2006; Tongway and Ludwig, 2003; Wang and Shao, 2013). Thus, maintaining spatial patterns of vegetation and soil heterogeneity should be primary goals for the sustainable management of grassland ecosystems (Pellant et al., 2000; Herrick et al., 2005).

Grazing intensity is a key management variable that influences the structure and composition of grassland ecosystems (Hickman et al., 2004; Bestelmeyer et al., 2009; Lin et al., 2010). In tallgrass prairie, grazing significantly increased species richness, diversity and forb cover (Hickman et al., 2004; Koerner and Collins, 2013). In subalpine grassland in the eastern Pyrenees (Andorra), heavy grazing increased species richness and diversity, but decreased forage quality and production (Komac et al., 2014). Overgrazing has profound effects on important ecosystem characteristics, such as water erosion (Cerdà and Lavee, 1999), soil water content (SWC) (Lin et al., 2010), soil organic carbon (SOC) ( $\mathrm{Su}$ et al., 2006; Costa et al., 2015), total nitrogen (TN) (Augus- 
tine and Frank, 2001; Lin et al., 2010; Hirobe et al., 2013), plant species richness and diversity (Gibson, 1988; Hickman et al., 2004; Ren et al., 2012; Angassa, 2014), belowground bud bank (Qian et al., 2014) and ecosystem stability (Su et al., 2006; Ren et al., 2012). However, the effects of livestock grazing on soil heterogeneity have not been consistent - with some studies showing that overgrazing increased soil heterogeneity of TN, SOC and fine soil proportion (Schlesinger et al., 1990; Su et al., 2006), while other studies reported that soil heterogeneity and vegetation diversity decreased from a patchy to a homogeneous distribution with increased grazing intensity (e.g., Zhao et al., 2011). Grazing increased spatial heterogeneity of vegetation (total vegetation cover) and soil properties (SOC, TN and the proportion of sand, silt and clay) in the semi-arid shrublands of northern Patagonia in South America (Kröpfl et al., 2013). However, results of Lin et al. (2010) showed that neither SOC nor soil $\mathrm{N}$ responded to grazing intensity at a large scale $(1-18 \mathrm{~m})$ but that overgrazing increased vegetation fragmentation $(<2 \mathrm{~m})$ in desert steppe of northern China. In a grazed ecosystem in Yellowstone National Park, grazing animals increased diversity of plant species at a fine scale $(20 \times 20 \mathrm{~cm})$ and altered the distribution of soil $\mathrm{N}$ across a topographic gradient at large spatial scales $(5-30 \mathrm{~m})$ with soil $\mathrm{N}$ properties exhibiting increased variance among sampling points at increasing distances from 5 to $30 \mathrm{~m}$. Ungrazed grasslands exhibited no spatial structure in soil $\mathrm{N}$ distribution with no topographic correlation (Augustine and Frank, 2001). In China, overgrazing was hypothesized to spatially homogenize SOC and total N pools at $2 \mathrm{~m}$ scales (Wiesmeier et al., 2009; Lin et al., 2010). However, Su et al. (2006) hypothesized that the lack of spatial heterogeneity of soil properties $(10 \mathrm{~m}$ scales) from overgrazing could not be reversed even when grazing was eliminated for 4 years. Therefore, the effects of grazing intensity on soil heterogeneity may be positive, negative or negligible depending on the level of grazing intensity and scale of observation (Fuhlendorf and Smeins, 1999).

Grasslands are used for livestock grazing extensively in the dry area of China, where grazing pressure may increase substantially in the future due to increasing demands for animal products (Han et al., 2008). The effects of grazing on spatial heterogeneity of grassland ecosystems as related to soil properties and vegetation have been inconsistent and need clarification. In this study, we hypothesized that a reduction in grazing intensity will alter soil spatial heterogeneity and vegetation characteristics in grasslands of northern China. The study aimed to quantify the effects of various grazing intensities on vegetation and soil spatial heterogeneity of SWC, SOC and TN at a $10 \mathrm{~m}$ scale in grasslands of Inner Mongolia.

\section{Materials and methods}

\subsection{Study area}

Our study site was located in a temperate grassland on the Mongolian Plateau at the Guyuan Experimental Station of China Agricultural University in Hebei Province of northern China $\left(41^{\circ} 4^{\prime} \mathrm{N}, 115^{\circ} 46^{\prime} \mathrm{E}\right.$; elevation $1380 \mathrm{~m}$ ) (Fig. 1). This region has a semiarid continental monsoon climate, which in summer (June-August) is warm and relatively rainy. Autumn, winter and spring seasons (September-May) are windy, cold and dry. Mean annual precipitation is about $400 \mathrm{~mm}$ but varies among years with strong seasonal variability (Ma et al., 2014). The coefficient of variation for annual precipitation ranges from 25 to $50 \%$. The rainy season in 2012 began in late June. Long-term mean (19522011) for annual air temperature of the region is $1^{\circ} \mathrm{C}$ with a mean minimum temperature in January of $-18.6^{\circ} \mathrm{C}$ and mean maximum temperature of $17.6^{\circ} \mathrm{C}$ in July. The mean frost-free growing season in the region is 85 to 95 days. Frequent droughts and low temperatures during the short growing season are usually the limiting factors for plant growth. The soil is a Kastanozems soil (FAO, 2006) or a Calcic Orthic Aridisol (USA classification, Soil Survey Staff, 2003). The soil has a sandy loam texture, and soil characteristics of the three grazed sites are presented in Table 1.

Vegetation of the study site is relatively homogeneous and is dominated by Leymus chinensis (Trin.) Tzvelev and Stipa krylovii Roshev., in association with Phragmites communis Trin., Cleistogenes chinensis (Maxim.) Keng., Carex duriuscula (Maxim.) Keng., Taraxacum mongolicum Hand.-Mazz., Artemisia frigida Willd. and Polygonum sibiricum Laxm.

\subsection{Experimental design}

Three grazing sites (each with $1.5 \mathrm{ha}$ ) were used in this study, which were located about 100 to $150 \mathrm{~m}$ apart within a 24 ha area (Zhu et al., 2015). The study region had been free grazed by beef cattle and sheep year round with an estimated stocking rate of 2-3 sheep unit ha ${ }^{-1}$ for more than 50 years prior to 2009 and was fenced in 2009 (Zhu et al., 2015). In 2010, three grazing intensities were set up: ungrazed (UG, 0 sheep/ha), moderate grazing (MG, 6.7 sheep ha ${ }^{-1}$ with 50 to $55 \%$ biomass removal and equal to 1.43 sheep $\mathrm{ha}^{-1} \mathrm{yr}^{-1}$ ) and heavy grazing ( $\mathrm{HG}, 9.3$ sheep ha ${ }^{-1}$ with 70 to $85 \%$ biomass removal and equal to 2.33 sheep $\mathrm{ha}^{-1} \mathrm{yr}^{-1}$ ). The HG site is typical of the historical grazing intensity in this area. The grazing period was about 3.5 months per year from 15 June to 30 September. The grazing gradient used in this study represented the range of grazing pressures that can be found in this region (Ma et al., 2014). At the MG and HG sites, there was a rubber trough with fresh water replaced each day and a plastic shed that sheltered the sheep. The sheep were free grazed at MG and HG sites during the grazing period. 
Table 1. Soil characteristics for ungrazed (UG), moderate grazing (MG) and heavy grazing (HG) sites (mean \pm standard error) at $10 \mathrm{~cm}$ soil depth. $(n=5)$.

\begin{tabular}{lllllllll}
\hline Grazed site & Soil pH & $\begin{array}{l}{ }^{1} \mathrm{SBD} \\
\mathrm{g} \mathrm{cm}^{-3}\end{array}$ & $\begin{array}{l}{ }^{2} \mathrm{SOC} \\
\mathrm{g} \mathrm{kg}^{-1}\end{array}$ & $\begin{array}{l}{ }^{3} \mathrm{STC} \\
\mathrm{g} \mathrm{kg}^{-1}\end{array}$ & $\begin{array}{l}{ }^{4} \mathrm{TN} \\
\mathrm{g} \mathrm{kg}^{-1}\end{array}$ & $\begin{array}{l}\text { Sand } \\
\%\end{array}$ & $\begin{array}{l}\text { Silt } \\
\%\end{array}$ & $\begin{array}{l}\text { Clay } \\
\%\end{array}$ \\
\hline UG & $9.2 \pm 0.1^{\mathrm{a}}$ & $1.3 \pm 0.0^{\mathrm{a}}$ & $12.3 \pm 2.0^{\mathrm{c}}$ & $21.9 \pm 2.0^{\mathrm{b}}$ & $1.6 \pm 0.1^{\mathrm{b}}$ & $47.3 \pm 24.5^{\mathrm{c}}$ & $49.5 \pm 18.4^{\mathrm{a}}$ & $3.2 \pm 1.7^{\mathrm{a}}$ \\
MG & $9.2 \pm 0.2^{\mathrm{a}}$ & $1.4 \pm 0.0^{\mathrm{a}}$ & $18.8 \pm 2.3^{\mathrm{ab}}$ & $31.00 \pm 0.4^{\mathrm{a}}$ & $2.4 \pm 0.1^{\mathrm{a}}$ & $50.0 \pm 25.6^{\mathrm{b}}$ & $46.7 \pm 20.6^{\mathrm{b}}$ & $3.2 \pm 1.4^{\mathrm{b}}$ \\
HG & $9.0 \pm 0.2^{\mathrm{a}}$ & $1.4 \pm 0.1^{\mathrm{a}}$ & $13.5 \pm 0.2^{\mathrm{bc}}$ & $28.0 \pm 1.0^{\mathrm{a}}$ & $2.2 \pm 0.2^{\mathrm{a}}$ & $53.9 \pm 23.8^{\mathrm{a}}$ & $43.0 \pm 16.8^{\mathrm{c}}$ & $3.1 \pm 1.8^{\mathrm{c}}$ \\
\hline
\end{tabular}

Means within a column with different letters are significantly different at $P<0.05 .{ }^{1} \mathrm{SBD}-$ soil bulk density; ${ }^{2} \mathrm{SOC}-$ soil organic carbon; ${ }^{3} \mathrm{STC}-$ soil total carbon; ${ }^{4}$ $\mathrm{TN}$ - soil total nitrogen. ${ }^{\mathrm{a}, \mathrm{b}, \mathrm{c}}$ display the significant differences for the soil characteristics between treatments.

\subsection{Measurements}

To evaluate the spatial patterns of soil and vegetation characteristics, we employed a modified sampling design of $\mathrm{Su}$ et al. (2006) and Lin et al. (2010). At each grazing site $(150 \times 100 \mathrm{~m})$, we established a sampling matrix consisting of 126 grids $(10 \times 10 \mathrm{~m})$. For soil sampling, about 70 intersecting cross-points were randomly marked (Fig. 2), two soil samples were taken at each transect point to a depth of $10 \mathrm{~cm}$ using a soil auger $(5 \mathrm{~cm}$ diameter) and samples were bulked to obtain a composite sample. There were 70 soil samples at each grazing site with a total of 210 soil samples. This allowed for an estimation of the effect of grazing intensity on soil characteristics at a $10 \mathrm{~m}$ scale. All plant litter was removed from the soil surface during soil sampling.

For vegetation sampling, $1210 \times 10 \mathrm{~m}^{2}$ grids were randomly chosen, and each of the grids was divided into 25 $2 \times 2 \mathrm{~m}^{2}$ subgrids (Fig. 2). One of the $4 \mathrm{~m}^{2}$ subgrids was used to measure canopy height, and two $0.25 \mathrm{~m}^{2}$ sub-subgrids were used to measure species richness and aboveground biomass. Soil and vegetation samples were collected in late July 2012. Species richness $(S)$ was calculated for each grazing site as the mean number of species per site, whereas species diversity was calculated using the Shannon-Wiener diversity index $\left(H^{\prime}\right)$, which is determined by the following equation:

$H^{\prime}=-\sum_{i=1}^{s} p_{i} \ln p_{i}$

where $s$ is the number of species and $p_{i}$ is the proportion of individuals belonging to the $i$ th species for each quadrat.

Aboveground biomass was clipped at ground level and separated into live and standing dead plant components, and litter was also collected in the quadrat. The live plant component was further subdivided into grasses and non-grasses. All plant samples were oven-dried at $65^{\circ}$ for 2 days, and then dry weights were determined. Soil bulk density was determined from five replicate samples using the ring-knife method (ISSCAS, 1978). Soil water content (SWC) was determined gravimetrically by oven-drying at $105^{\circ}$ for $48 \mathrm{~h}$. Debris and gravel were separated from the soil samples, airdried and passed through a $2 \mathrm{~mm}$ sieve. Soil particle size was determined by the wet sieve method (ISSCAS, 1978). Subsamples were finely ground to pass a $0.25 \mathrm{~mm}$ sieve and analyzed for SOC and TN. A Rapid C Analyzer (Elementer, Germany) was used to determine SOC. TN was determined by the Kjeldahl Method (ISSCAS, 1978).

\subsection{Statistical analysis}

Means, standard deviations (SDs) and coefficients of variation (CVs) were calculated for all data. Data were tested for normality distribution using the Kolmogorov-Smirnov test, kurtosis and skewness. For a normal distribution, the skewness is 0 and the kurtosis is 3 . Differences of soil properties and vegetation characteristics between grazing intensities were evaluated using one-way analysis of variance (ANOVA). Values of sampling points from each transect were averaged within each grazed plot and then ANOVA analysis was performed. Tukey's Studentized range (honest significant difference - HSD) test for multiple comparisons was used with $P<0.05$. All statistical analyses were conducted with SAS 9.2.

The spatial patterns of SWC, SOC and total TN were analyzed geostatistically using semivariograms. Semivariances were calculated for the field data using $\mathrm{GS}^{+}$(Version 7.0, Gamma Design Software) and models were fit to semivariograms using best-fit procedures. Best-fit model parameters for the semivariograms were calculated based on the smallest residual sum of square (RSS). The semivariance $(\Upsilon(h))$ for each specific lag distance $(h)$ was calculated using the formula

$\gamma(h)=\frac{1}{2 N(h)} \sum_{i=1}^{N(h)}\left[z\left(x_{i}\right)-z\left(x_{i}+h\right)\right]$,

where $N(h)$ is the number of pairs separated by distance $h$, $Z\left(x_{i}\right)$ is the measured sample value at spatial location $x_{i}$ and $z\left(x_{i}+h\right)$ is the value of the measured variable at spatial location $x_{i}+h$ (Isaaks and Srivastava, 1989; Rossi et al., 1992). A variogram function was determined by three parameters: the nugget effect, range and sill. The nugget effect $\left(\mathrm{C}_{0}\right)$ is either the variance within the sampling unit or represents a spatial dependence at a scale smaller than the minimum distance examined. The range is the scale of spatial 


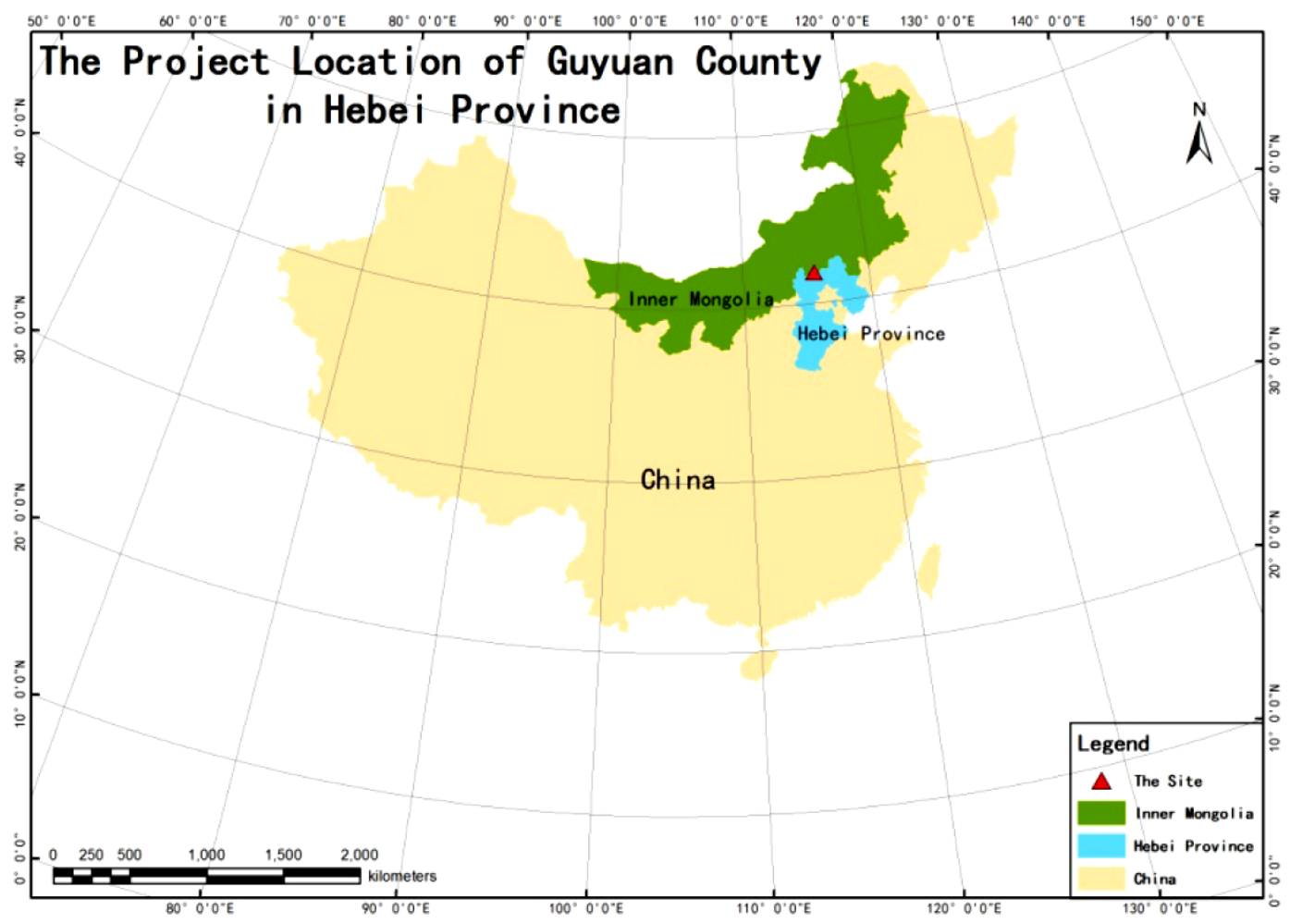

Figure 1. Project location in Guyuan County, Hebei Province in northern China.

autocorrelation and is estimated by the maximum distance at which pairs of sampling points are separated. The sill (C $+\mathrm{C}_{0}$ ) is the maximum semivariance of all sampling points. The proportion of nugget $\left(\mathrm{C}_{0}\right)$ to the estimated total sample variation (sill, $\mathrm{C}+\mathrm{C}_{0}$ ) was used as a criterion to classify the spatial dependence of soil properties. In this study, we followed the classification criterion of Cambardella et al. (1994), which classifies the variable into strong spatial dependence $(<25 \%)$, moderate spatial dependence $(25-75 \%)$ and weak spatial dependence $(>75 \%)$. For the measured data with a spatial patterned distribution, the semivariance is relatively small at short lag distances, which indicates that neighboring samples are more similar and autocorrelated, whereas the semivariance is relatively large when the paired sample becomes less similar. Ordinary kriging was used as an interpolating method based on spatial structure.

\section{Results}

\subsection{Ground cover characteristics}

Aboveground biomass was $220 \mathrm{~g} \mathrm{~m}^{-2}$ at the UG site, which was significantly greater than that at the MG $\left(99 \mathrm{~g} \mathrm{~m}^{-2}\right)$ and HG site $\left(27 \mathrm{~g} \mathrm{~m}^{-2}\right)(P<0.05)$ (Fig. 3). Standing dead or litter was not observed at the HG site, and only a relatively small amount of standing dead $\left(8.68 \mathrm{~g} \mathrm{~m}^{-2}\right)$ or litter $\left(13.41 \mathrm{~g} \mathrm{~m}^{-2}\right)$ was present at the MG site. Green biomass was $115 \mathrm{~g} \mathrm{~m}^{-2}$ at the UG site, which was also significantly greater than that at the MG and $\mathrm{HG}$ site (Fig. 4a). Grass was the dominant biomass component at all three sites, comprising 91,84 and $52 \%$ of live biomass at the UG, MG and HG sites, respectively (Fig. 4b). Non-grass biomass comprised 8 , 16 and $48 \%$ of live biomass at the UG, MG and HG sites, respectively (Fig. 4c).

Species richness at the $0.25 \mathrm{~m}^{2}$ scale was not significantly different $(P<0.05)$ between the MG (5.5) and HG site (5.7), which were significantly greater than the UG site (3.6) (Fig. 5a). The $\alpha$ diversity indices for the UG, MG and HG sites were significantly different $(P<0.05)$ with values of $0.43,0.80$ and 1.18 , respectively (Fig. $5 b$ ).

\subsection{Soil properties and their spatial characteristics}

The soil variability data in Table 2 showed that all CVs were between 10 and $45 \%$, which indicated that the soil properties examined in the study were moderately variable. The highest $\mathrm{CV}$ values were observed for SOC compared to the other soil characteristics. The CV values for SOC was higher for the MG and HG sites than UG site, indicating that grazed soils had a higher degree of variability for SOC. There was little difference between the median and the mean values for $\mathrm{TN}$ at the $\mathrm{HG}$ and MG sites. Greater differences were observed for SWC at the MG and HG sites compared to the UG site.

The normality results using frequency distribution and Kolmogorov-Smirnov tests showed that all the variables 
Table 2. Statistical characteristics of soil properties at sites exposed to different grazing intensities (UG - ungrazed, MG - moderate grazing and HG-heavy grazing).

\begin{tabular}{llrrrrrrrr}
\hline Variables & Treatment & Mean & SD & CV & Median & Max. & Min. & Skewness & Kurtosis \\
\hline SWC & UG & 19.2 & 3.0 & 15.6 & 19.1 & 27.0 & 13.7 & 0.25 & -0.36 \\
$(\%)$ & MG & 24.1 & 3.5 & 14.6 & 15.9 & 31.4 & 12.6 & -0.87 & 1.63 \\
& HG & 16.9 & 4.1 & 24.5 & 24.4 & 26.1 & 7.0 & 0.10 & -0.62 \\
\hline SOC & UG & 12.2 & 4.1 & 33.4 & 11.3 & 22.8 & 5.7 & 0.52 & -0.54 \\
$\left(\mathrm{~g} \mathrm{~kg}^{-1}\right)$ & MG & 18.2 & 6.5 & 35.6 & 18.8 & 31.7 & 6.0 & 0.13 & -0.76 \\
& HG & 15.9 & 6.7 & 44.8 & 15.5 & 34.8 & 5.1 & 0.86 & 0.27 \\
\hline Total N & UG & 1.6 & 0.4 & 28.4 & 1.5 & 2.6 & 0.7 & 0.50 & 0.19 \\
$\left(\mathrm{~g} \mathrm{~kg}^{-1}\right)$ & MG & 2.5 & 0.6 & 24.5 & 2.5 & 3.9 & 0.9 & -0.30 & 0.04 \\
& HG & 2.2 & 0.6 & 28.6 & 2.1 & 3.7 & 1.0 & 0.45 & -0.17 \\
\hline
\end{tabular}

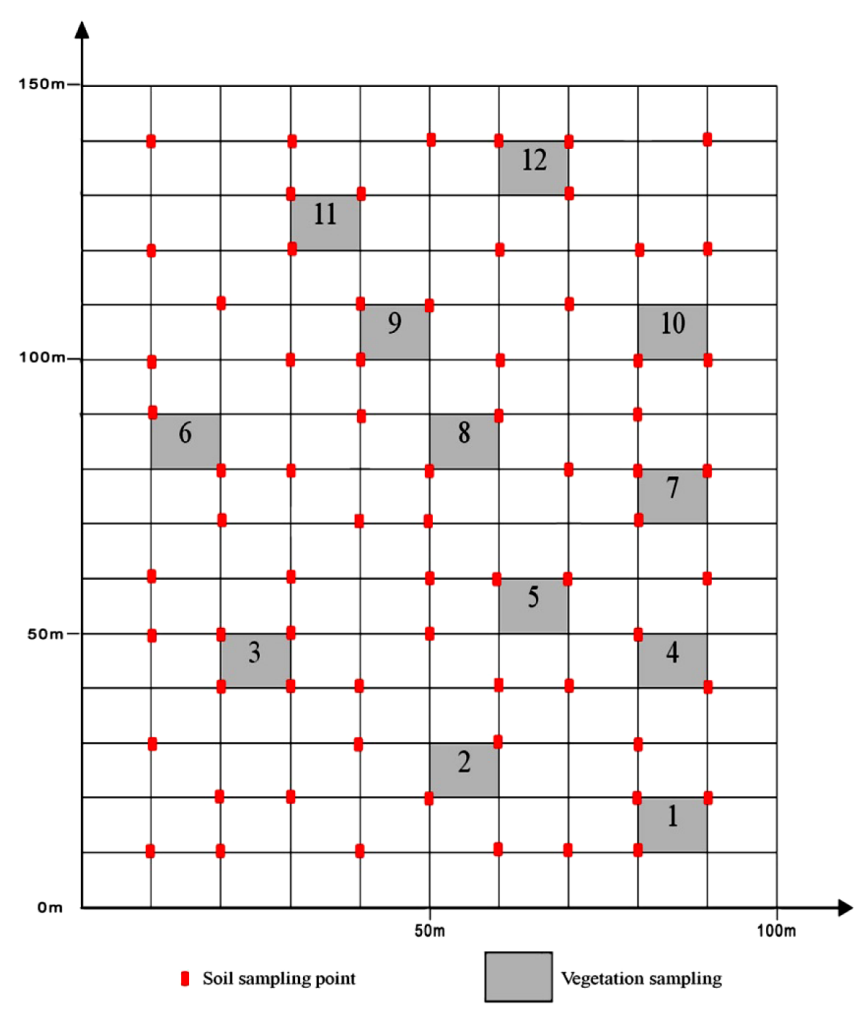

Figure 2. Soil and vegetation sampling points at one of the study sites.

were normally distributed. Semivariograms were constructed for each soil property to evaluate the spatial variation of soil properties. Semivariograms were fitted to spherical, exponential or Gaussian models (Table 3). Semivariances for soil properties were generally lower at the UG site than the MG and HG sites (Fig. 6). A relatively large nugget value means that the random portion of spatial variability and field variation within the minimum sampling spacing was quite large compared to the sill. The largest nugget value was observed at the HG site for $\operatorname{SOC}\left(\mathrm{C}_{0}=11.2\right)$. The nugget

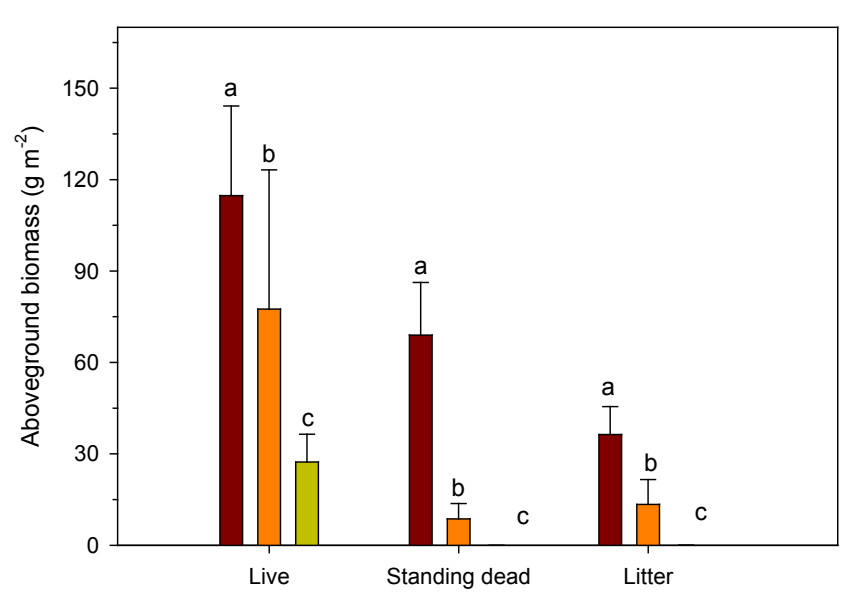

Figure 3. Aboveground biomass at sites exposed to three grazing intensities (UG - ungrazed, MG - moderate grazing, HG - heavy grazing). Different letters mean significance at $P<0.05$.

value for SWC was larger at the MG site $\left(\mathrm{C}_{0}=9.2\right)$ than UG $\left(\mathrm{C}_{0}=0.3\right)$ and $\mathrm{HG}\left(\mathrm{C}_{0}=2.6\right)$ sites (Table 3$)$. Sill values represented the estimated total sample variation and were generally higher for the MG and HG sites than UG site. All soil characteristics evaluated in our study showed a strong spatial dependence with the proportion of nugget variance to sill for each soil property $\left[\mathrm{C}_{0} /\left(\mathrm{C}+\mathrm{C}_{0}\right)\right]$ ranging from 0 to $23 \%$. The proportion of sample variance explained by small-scale patchiness $\left[\mathrm{C}_{0} /\left(\mathrm{C}+\mathrm{C}_{0}\right)\right]$ was especially low at the UG site for SWC and TN suggesting that the UG site had a higher degree of fine-grained variability for these soil characteristics compared to the MG and HG sites. The range of autocorrelation $\left(\mathrm{A}_{0}\right)$ for TN was 15.0 and $20.8 \mathrm{~m}$ for the UG and MG sites, respectively, and for SOC was 8.6 and $17.3 \mathrm{~m}$ for the UG and MG sites, respectively, which was less than that for the HG site in both cases (>120 m).

Spatial distribution is highlighted as the area where there is a high and low content of the studied variables, which are shown in Fig. 7. In general, the maps showed high het- 

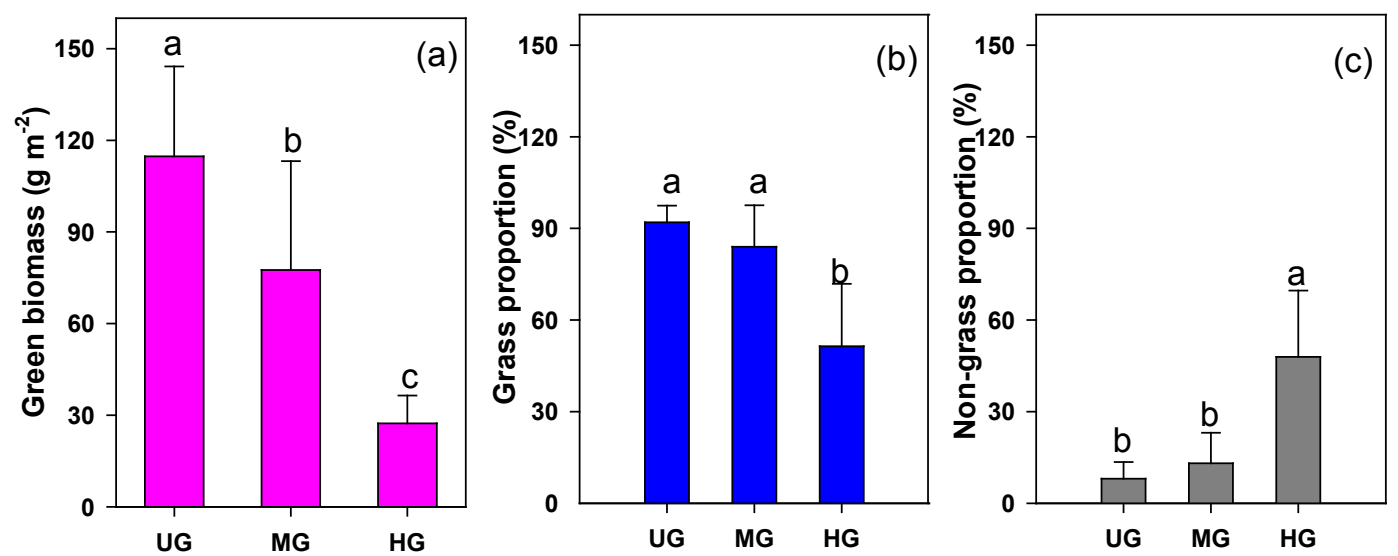

Figure 4. Green biomass (a), grass composition proportion (b) and non-grass composition proportion (c) at sites exposed to three grazing intensities (UG - ungrazed, MG - moderate grazing, HG - heavy grazing). Bars represent + standard error. Different letters mean significant difference at $P<0.05$.
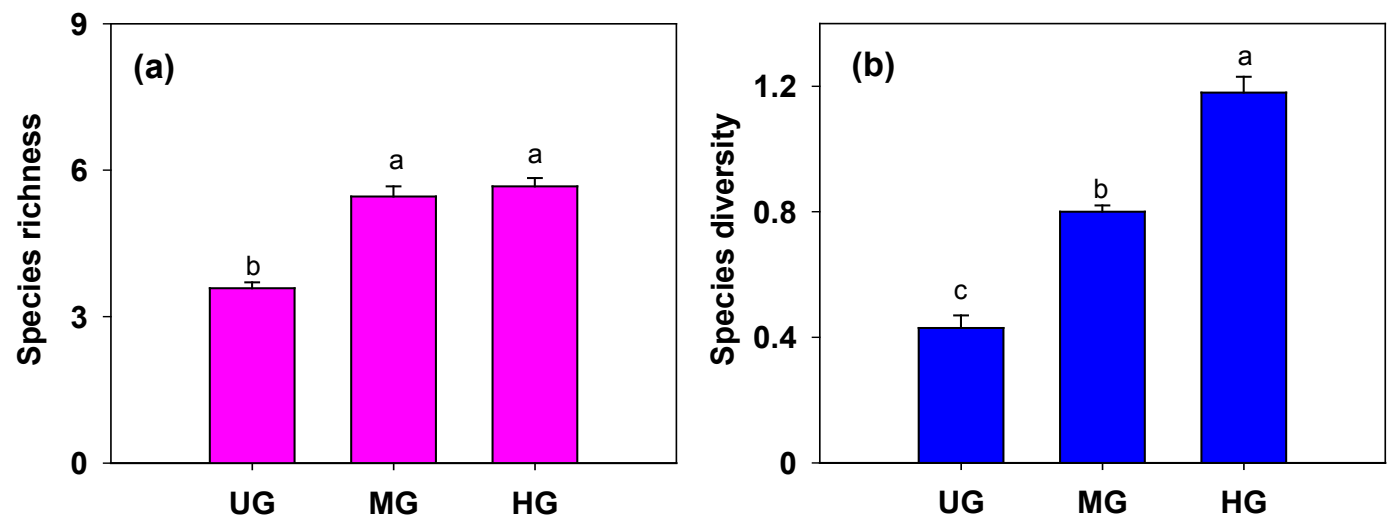

Figure 5. Species richness (a) and alpha diversity (b) at $0.25 \mathrm{~m}^{2}$ scale for sites exposed to three grazing intensities (UG - ungrazed, MGmoderate grazing, $\mathrm{HG}$ - heavy grazing). Bars represent + standard error. Different letters mean significant difference at $P<0.05$.

erogeneity, and the degree of patch fragmentation for SWC, SOC and TN was higher at the UG and MG sites than HG site. Within the same plot, SOC and total $\mathrm{N}$ exhibited similar spatial patterns with generally low levels of SOC and TN.

\section{Discussion}

\subsection{Aboveground cover characteristics}

Livestock overgrazing in the dry steppe exerts a strong influence on ecosystem dynamics by decreasing vegetative biomass, and changing species composition and soil properties (Rietkerk et al., 2000; Augustine and Frank, 2001; Kondo et al., 2011). Grazing affects plant diversity in many ecosystems (Milchunas and Lauenroth, 1993; Hoshino et al., 2009) and generally increases plant diversity through reductions in competition (Collins et al., 1998) and creation of environmental heterogeneity at different spatial scales (McNaughton, 1983; Sommer, 2000). Grazing and exclosure studies conducted by Oba et al. (2001) in arid grasslands of northern Kenya indicated that maximum plant-species richness occurred at an intermediate level of biomass production. However, the link between plant-species richness and biomass in their study was not direct and was hypothesized to be influenced by factors such as SWC, soil type, time of year and type of management. Our study demonstrated that vegetation characteristics changed significantly with grazing (Figs. 3-5). These effects of grazing were probably caused by decreased total biomass (live, standing dead and litter) (Su et al., 2006; Lin et al., 2010; Komac et al. 2014), changes in species composition (Augustine and Frank, 2001; Hickman et al. 2004; Koerner and Collins, 2013) and decreased input of organic matter (Zhao et al., 2005; Su et al., 2006; Lin et al., 2010). Similar results were observed in the tallgrass prairie of the USA (Hickman et al. 2004; Koerner and Collins, 2013), a semi-arid grassland in the Mediterranean Region (Komac et al., 2014) and Euro-Asian steppes (Zhao et al., 2005; Lin et al., 2010). 
(a) SWC
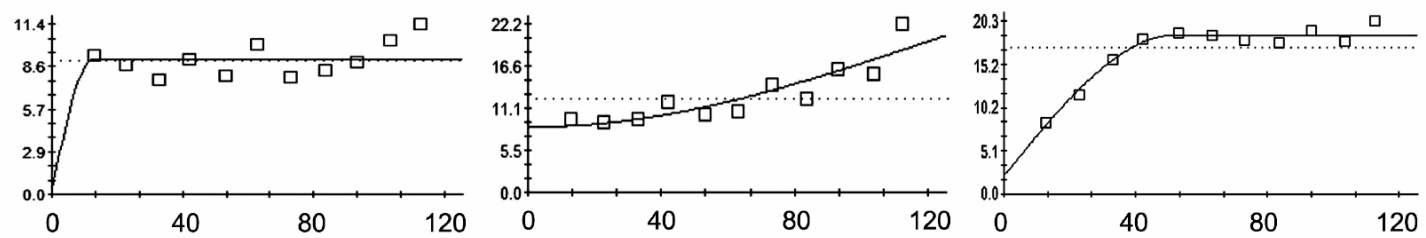

(b) SOC
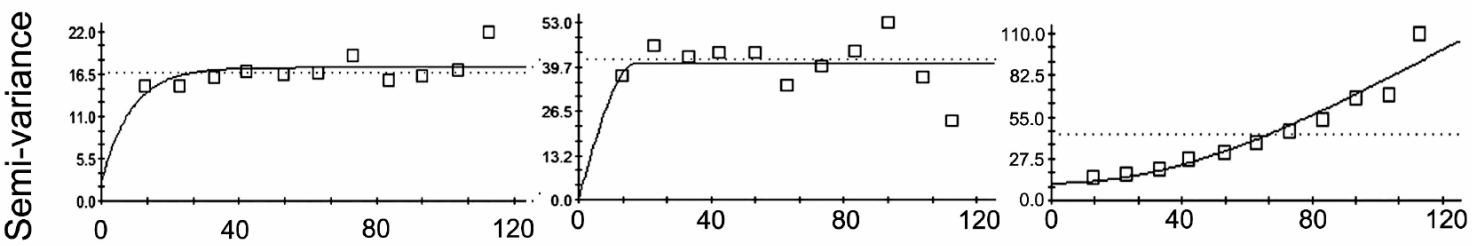

(c) TN

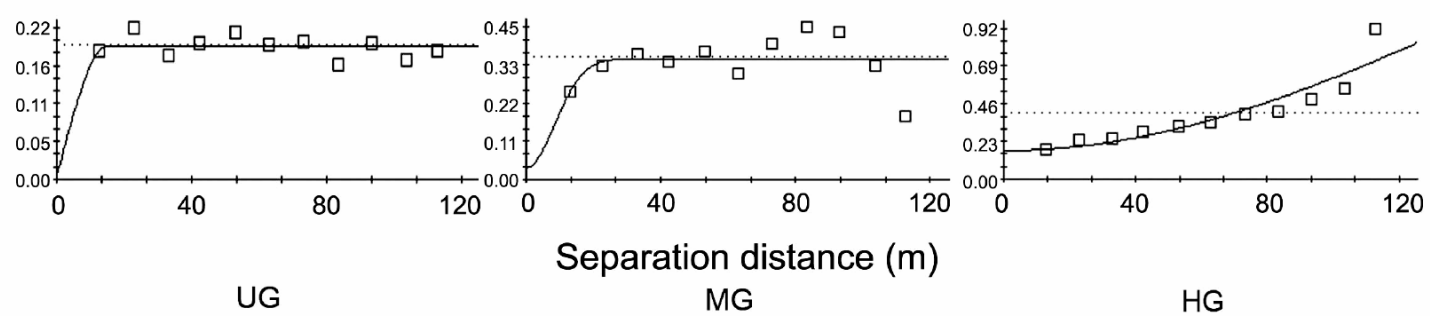

Figure 6. Semivariograms for soil water content (SWC) (a), soil organic C (SOC) (b), soil total N (c) for sites exposed to three grazing intensities: ungrazed (UG, first column), moderate grazing (MG, second column) and heavy grazing (HG, third column).

Table 3. Summary of semivariogram model parameters for ungrazed (UG), moderate grazing (MG) and heavy grazing (HG) sites.

\begin{tabular}{lllrrrrrr}
\hline Property & Site & Model & RSS $^{\mathrm{a}}$ & $r^{2}$ & $\begin{array}{r}\text { Nugget }^{\mathrm{b}} \\
\left(\mathrm{C}_{0}\right)\end{array}$ & $\begin{array}{r}\text { Sill }^{\mathrm{c}} \\
\left(\mathrm{C}_{0}+\mathrm{C}\right)\end{array}$ & $\begin{array}{r}\text { Range }^{\mathrm{d}} \\
\left(\mathrm{A}_{0}\right)(\mathrm{m})\end{array}$ & $\begin{array}{r}\text { Nugget/sille }^{\mathrm{e}} \\
(\%)\end{array}$ \\
\hline SWC & UG & Spherical & 13.4 & 0.00 & 0.3 & 9.1 & 12.7 & 3.3 \\
$(\%)$ & MG & Gaussian & 27.3 & 0.82 & 8.6 & 38.2 & $>120$ & 22.5 \\
& HG & Spherical & 5.5 & 0.96 & 2.1 & 19.0 & 52.3 & 11.1 \\
\hline SOC & UG & Exponential & 32.8 & 0.19 & 2.3 & 17.3 & 8.6 & 13.3 \\
$\left(\mathrm{~g} \mathrm{~kg}^{-1}\right)$ & MG & Spherical & 567.0 & 0.02 & 0.1 & 41.0 & 17.3 & 0.2 \\
& HG & Gaussian & 554 & 0.93 & 11.2 & 223.0 & $>120$ & 5.0 \\
\hline Total N $\left.^{-1}\right)$ & UG & Spherical & 0.003 & 0.01 & 0.0 & 0.2 & 15.0 & 0 \\
$\left(\mathrm{~g} \mathrm{~kg}^{-1}\right)$ & MG & Gaussian & 0.05 & 0.15 & 0.0 & 0.4 & 20.8 & 0 \\
& HG & Gaussian & 0.06 & 0.85 & 0.2 & 2.4 & $>120$ & 8.3 \\
\hline
\end{tabular}

${ }^{a}$ RSS - residual sum of squares. ${ }^{b}$ Nugget $\left(\mathrm{C}_{0}\right)$ - spatial dependence at a scale smaller than the minimum distance examined. ${ }^{c}$ Sill $\left(\mathrm{C}_{0}+\mathrm{C}\right)$ - estimated total sample variation. ${ }^{\mathrm{d}}$ Range - range of spatial dependency or autocorrelation. ${ }^{\mathrm{e}}$ Nugget/sill-magnitude of spatial dependence.

In our study, after sheep grazing was excluded for 4 years at the UG site and grazing intensity was reduced at the MG site, vegetation recovered to some extent at these sites. Moreover, vegetation characteristics differed significantly from those at the HG site where heavy grazing was continuous for another 4 years. The results showed that vegetation composition and biomass characteristics could be improved even in a period of 4 years. However, Ren et al. (2012) also working in the steppes of Inner Mongolia showed that plant species composition and diversity varied among years, were primarily determined by precipitation and temperature and were little affected by grazing intensity. In our study, grazing increased species richness and diversity, especially at the HG site. The proportion of grass in total biomass decreased with increasing grazing intensities, whereas the non-grass proportion showed the opposite trend. The probable reason may 
(a) SWC (\%)
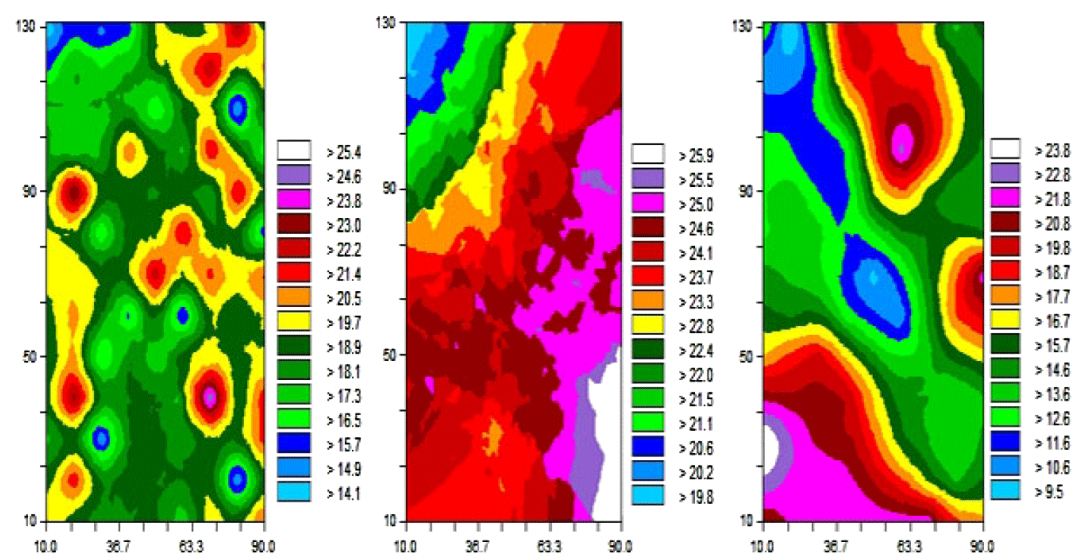

(b) SOC $\left(\mathrm{g} \mathrm{kg}^{-1}\right)$
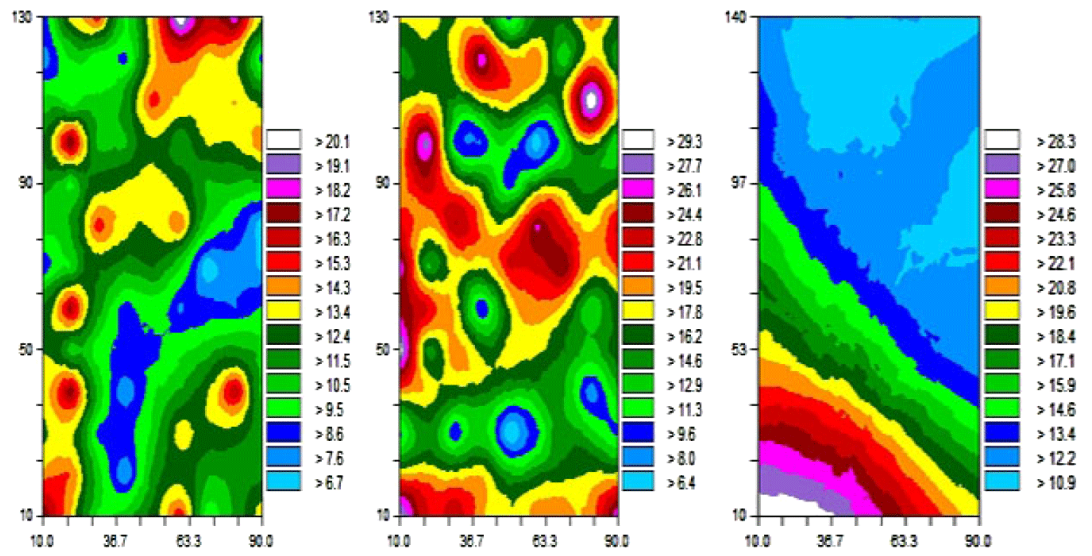

(c) TN $\left(\mathrm{g} \mathrm{kg}^{-1}\right)$
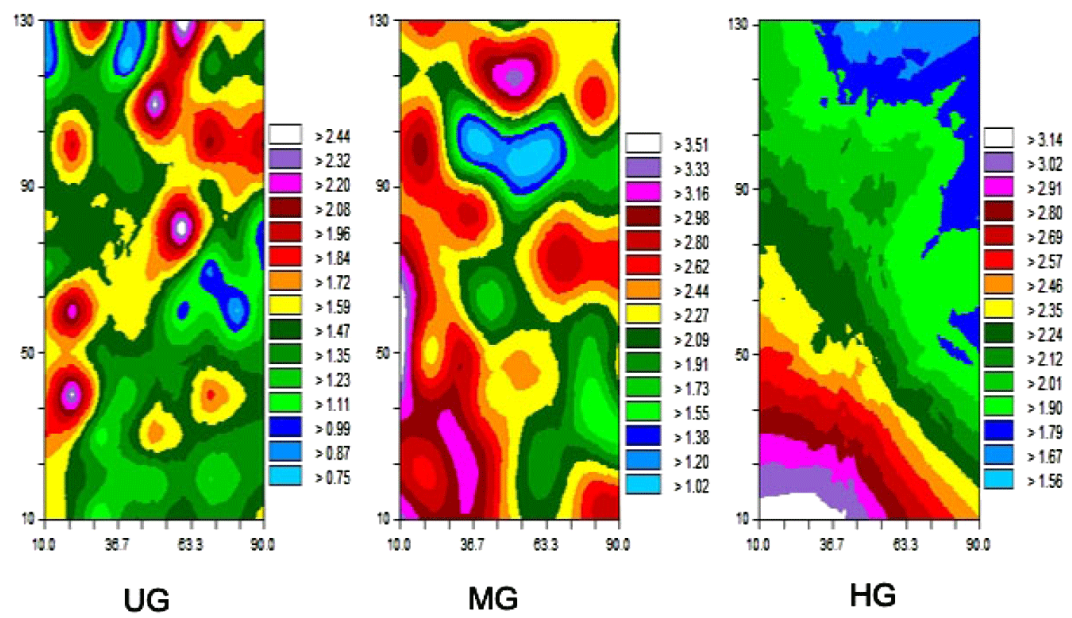

Figure 7. Spatial distribution of (a) soil water content (SWC), (b) soil organic carbon (SOC) and (c) soil total nitrogen (TN) under three different grazing intensities: ungrazed (UG, first column), moderate grazing (MG, second column) and heavy grazing (HG, third column). 
be that heavy grazing removed a large proportion of the aboveground biomass (especially grass biomass), which correspondingly decreased plant cover and opened niches for non-grass species. This agrees with the results of Augustine and Frank (2001) who found that greater plant diversity $(20 \times 20 \mathrm{~cm})$ was observed in small patches in grazed grassland in Yellowstone National Park in the USA. Results concerning the effect of grazing on vegetation variation and spatial heterogeneity patterns sometimes differ depending on how plant diversity is defined and the particular methods used (Adler et al., 2001). The effect of grazing on plant diversity also may be related to the measurement scale, as indicated by Augustine and Frank (2001) who found that grazed grassland exhibited greater plant diversity at small scales $(20 \times 20 \mathrm{~cm})$ compared to large scales $(4 \times 4 \mathrm{~m})$. In our study, vegetation variation was measured at a $50 \mathrm{~cm}^{2}$ scale, a relatively small scale.

\subsection{Soil spatial properties as affected by grazing}

In the present study, we determined the magnitude of soil heterogeneity under three grazing intensities at a $10 \mathrm{~m}$ scale. Descriptive statistics revealed that $\mathrm{CVs}$ for the tested soil properties were $14-45 \%$ and displayed moderate variability according to the criteria of Zhang et al. (2007). The variability of SOC for all the sites was greater than that for TN and SWC, especially SOC for the HG site, which had the greatest variability. This may be related to reduced litter input with heavy grazing and more livestock excreta patches with heavy grazing. The variation of SWC was greater at the MG and HG sites than UG site.

Our results showed that the ranges of spatial autocorrelation for SWC, SOC and TN were smaller at the UG and MG sites than HG site. These results indicated that soil characteristics were relatively uniform across the HG site compared to the UG and MG sites at the examined scale. The results also indicated that the soil sampling spacing for SOC and $\mathrm{TN}$ from the grazed grassland can be greater $(>120 \mathrm{~m}$ for HG site and $>20 \mathrm{~m}$ ) and less sampling density at the grazed sites due to a greater $A_{0}$ (Chien et al., 1997). Grazing had a strong influence on the spatial patterns of soil characteristics and was the main reason for changed spatial autocorrelation in grasslands of Turkey (Ozgoz et al., 2013), which may have resulted in soil and vegetation characteristics being relatively homogeneous at grazed sites and heterogeneous at ungrazed sites in China (Zhao et al., 2011). Hirobe et al. (2013) also reported that grazing in Mongolian grasslands homogenized the spatial patterns of net $\mathrm{N}$ mineralization and net nitrification, which were not related to their original spatial patterns and were largely determined by differences in vegetation structure. This was probably due to heavy grazing reducing the input rate of organic matter, decreasing plant cover, trampling damage to plant tissue, increasing soil bulk density and decreasing soil water infiltration. However, Su et al. (2006) found greater spatial variability in soil characteris- tics on sites rested for five years after heavy grazing, which is inconsistent with our findings. A possible reason for this discrepancy may be that Su et al. (2006) conducted their study in sand dune vegetation compared to steppe vegetation in our study, where the distribution of soil properties and vegetation was not uniform across different types of sand dunes.

Soil physical characteristics have been shown to be the main factors controlling spatial patterns of soil water and soil nutrients (Zhao et al., 2011). Soil compaction following heavy grazing can lead to a homogeneous spatial distribution of soil characteristics and increase the vulnerability of soil water and soil loss, and consequently reduce water availability for plants and rangeland production (Zhao et al., 2011). With increasing grazing intensity, heterogeneity of soil and plant characteristics changed from a patchy to a homogeneous distribution (Zhao et al., 2011). This was also confirmed in our study where heavy grazing decreased variation in soil properties (SWC, SOC, TN) at the $10 \mathrm{~m}$ scale, strongly modified soil property patterns and changed species composition. In our study, 4 years after grazing intensity was changed from heavy grazing to moderate grazing at the MG site, spatial variability of soil properties increased at the MG site compared to the HG site. Livestock grazing resulted in changes to litter input, which may have influenced SOC (Zhao et al., 2005; Su et al., 2006; Lin et al., 2010; Komac et al., 2014). Although Lin et al. (2010) thought those factors resulted in a more homogeneous grazing distribution, they were not strong enough to alter the pre-existing spatial patterns of vegetation and soil fertility in their desert steppe. They found that neither SOC nor total $\mathrm{N}$ responded to grazing intensity at a coarse scale (1-18 m), while soil water content and SOC decreased with increasing grazing intensity at a fine scale $(<2 \mathrm{~m})$ (Lin et al., 2010). Our findings from the typical steppe confirmed that livestock grazing can change the spatial patterns of soil properties at a $10 \mathrm{~m}^{2}$ scale and make them more homogeneous. The heterogeneity of SOC patches decreased with increasing grazing pressure, which was in agreement with the long-term ( $>25$ years) responses of SOC spatial patterns to grazing in a semi-arid steppe in Inner Mongolia (Wiesmeier et al., 2009). This was also confirmed by the findings of Augustine and Frank (2001) who found that semivariance was positively correlated with distance between sampling points in grazed grassland at Yellowstone National Park, indicating that homogeneous patches occurred at a scale $>30 \mathrm{~m}$ for soil $\mathrm{N}$.

The responses of spatial patterns to grazing depend on the scale at which they are measured (Augustine and Frank, 2001; Lin et al., 2010; Zhao et al., 2011). At small scales $(10-200 \mathrm{~cm})$, removal of grazers increased patchiness in soil $\mathrm{N}$, while grazed grassland exhibited extremely fine-grained $(<10 \mathrm{~cm})$ variability (Augustine and Frank, 2001). At larger spatial scales extending across a topographic gradient, soil $\mathrm{N}$ properties exhibited no spatial structure in ungrazed grassland, while homogeneous patches for soil $\mathrm{N}$ occurred at a scale of $30 \mathrm{~m}$ in grazed grassland (Augustine and Frank, 
2001). Lin et al. (2010) found that in some fragile areas, grazing could lead to a high degree of spatial heterogeneity in soil characteristics, which resulted in land degradation/desertification. These studies indicated that additional documentation is needed to clarify how the interactive effects of grazing and physical environment affect ecosystem heterogeneity at different spatial scales.

\section{Conclusions}

This study contributes to the understanding of the ecological effects of grazing on the soil and vegetation characteristics of steppe grasslands in northern China. The nugget ratio of SWC, SOC and TN was about 0 to $23 \%$, indicating that the spatial correlation had strong spatial dependence. We found that reducing livestock grazing intensity increased the heterogeneity of soil characteristics at a $10 \mathrm{~m}$ scale. As expected, grazing markedly reduced vegetation biomass under heavy and moderate grazing. In addition, grazing increased the nongrass component of the vegetation, and species richness and diversity increased. Little heterogeneity was observed for soil characteristics at scales $>10 \mathrm{~m}$ under heavy grazing. A lower sampling density could be used at the HG site compared to the UG and MG sites. For this agro-pastoral area of northern China, livestock grazing should be reduced to restore heterogeneity of soil properties and aboveground biomass. One alternative is to feed sheep in feedlots during the non-growing season, which may help in restoring heterogeneity of soil and vegetation characteristics.

Author contributions. Yuping Rong and Zhongmei Wang designed the experiments, Zhongmei Wang carried them out. Zhongmei Wang, Douglas A. Johnson and Yuping Rong interpreted the results and prepared the paper.

Acknowledgements. Research was funded by the National Natural Science Foundation of China (31472136) and Modern Agroindustry Technology Research System under grant (CARS-35) and National Basic Research Program of China (2014CB138805). Assistance with data collection by Fei Yuan, Lei Ma and Min Zhao is gratefully appreciated. We thank the two anonymous reviewers for their constructive comments.

Edited by: P. Pereira

\section{References}

Adler, P. B., Raff, D. A., and Lauenroth, W. K.: The effect of grazing on the spatial heterogeneity of vegetation, Oecologia, 128, 465479, 2001

Angassa, A.: Effects of grazing intensity and bush encroachment on herbaceous species and rangeland condition in southern Ethiopia, Land Degrad. Dev., 25, 438-451, 2014.
Augustine, D. J. and Frank, D. A.: Effects of migratory grazers on spatial heterogeneity of soil nitrogen properties in a grassland ecosystem, Ecology, 82, 3149-3162, 2001.

Bestelmeyer, B. T., Tugel, A. J., Peacock, G. L., Robinett, D. G., Shaver, P. L., Brown, J. R., Herrick, J. E., Sanchez, H., and Havstad, K. M.: State-and-transition models for heterogeneous landscapes: A strategy for development and application, Rangeland Ecol. Manage., 62, 1-15, 2009.

Cambardella, C. A., Moorman, T. B., Novak, J. M., Parkin, T. B., Karlen, D. L., Turco, R. F., and Konopka, A. E.: Field-scale variability of soil properties in central Iowa soils, Soil Sci. Soc. Am J., 58, 1501-1511, 1994.

Cerdà, A. and Lavee, H.: The effect of grazing on soil and water losses under arid and Mediterranean climates, Implications for desertification, Pirineos, 153/154, 159-174, 1999.

Chien, Y. J., Lee, D. Y., Guo, H. Y., and Houng, K. H.: Geostatistical analysis of soil properties of mid-west Taiwan soils, Soil Sci., 162, 291-298, 1997.

Collins, S. L., Knapp, A. K., Briggs, J. M., Blair, J. M., and Steinauer, E. M.: Modulation of diversity by grazing and mowing in native tallgrass prairie, Science, 280, 745-747, 1998.

Costa, C., Papatheodorou, E. M., Monokrousos, N., and Stamou, G. P.: Spatial variability of soil organic $\mathrm{C}$, inorganic $\mathrm{N}$ and extractable $\mathrm{P}$ in a Mediterranean grazed area, Land Degrad. Dev., 26, 103-109, 2015.

FAO World Reference Base for Soil Resources: A framework for international classification, correlation and communication, World Soil Resources Reports 103, FAO, Rome, Italy, 2006.

Fuhlendorf, S. D. and Smeins, F. E.: Scaling effects of grazing in a semi-arid savanna, J. Veg. Sci., 10, 731-738, 1999.

García-Palacios, P., Maestre, F. T., and Gallardo, A.: Soil nutrient heterogeneity modulates ecosystem responses to changes in the identity and richness of plant functional groups, J. Ecol., 99, 551562,2011

Gibson, D. J.: The relationship of sheep grazing and soil heterogeneity to plant spatial patterns in dune grassland, J. Ecol., 76, 233-253, 1988.

Han, J. G., Zhang, Y. J., Wang, C. J., Bai, W. M., Wang, Y. R., Han, G. D., and Li, L. H.: Rangeland degradation and restoration management in China, Rangeland J., 30, 233-239, 2008.

Herrick, J. E., Van Zee, J. W., Havstad, K. M., Burkett, L. M., and Whitford, W. G.: Monitoring manual for grassland, shrubland and savanna ecosystems, Volume II: Design, supplementary methods and interpretation. USDA-ARS Jornada Experimental Range, Las Cruces, NM, University of Arizona Press: Tucson, AZ, 2005.

Hickman, K. R., Hartnett, D. C., Cochran, R. C., and Owensby, C. E.: Grazing management effects on plant species diversity in tallgrass prairie, J. Range Manage., 57, 58-6, 2004.

Hirobe, M., Kondo, J., Enkhbaatar, A., Amartuvshin, N., Fujita, N., Sakamoto, K., Yoshikawa. K., and Kielland, K.: Effects of livestock grazing on the spatial heterogeneity of net soil nitrogen mineralization in three types of Mongolian grasslands, J. Soil Sediment, 13, 1123-1132, doi:10.1007/s11368-013-0702-6, 2013.

Hoshino, A., Yoshihara, Y., Sasaki, T., Okayasu, T., Jamsran, U., Okuro, T., and Takeuchi, K.: Comparison of vegetation changes along grazing gradients with different numbers of livestock, J. Arid Environ., 73, 687-690, 2009. 
Isaaks, E. H. and Srivastava, R. M.: An introduction to applied geostatistics. Oxford Univ. Press: New York, NY, 561 pp., 1989.

ISSCAS (Institute of Soil Sciences, Chinese Academy of Sciences), Physical and chemical analysis methods of soils, Shanghai Science Technology Press: Shanghai, China, 593 pp., 1978 (in Chinese).

Koerner, S. E. and Collins, S. L.: Small-scale patch structure in North American and South African grasslands responds differently to fire and grazing, Landscape Ecol., 28, 1293-1306, 2013.

Komac, B., Domènech, M., and Fanlo, R.: Effects of grazing on plant species diversity and pasture quality in subalpine grasslands in the eastern Pyrenees (Andorra): Implications for conservation, J. Nat. Conserv., 22, 247-255, 2014.

Kondo. J., Hirobe, M., Uugantsetseg, K., Amartuvshin, N., Fujita, N., Sakamoto, K., and Yoshikawa, K.: Effects of livestock grazing on the surface soil properties in Mongolian steppe ecosystems along an aridity gradient, J. Japan. Soc. Rev. Tech., 36, 406415, 2011

Kröpfl, A. J., Cecchi, G. A., Villasuso, N. M., and Distel, R. A.: Degradation and recovery processes in semi-arid patchy rangelands of northern Patagonia, Argentina, Land Degrad. Dev., 24, 393-399, 2013.

Lin, Y., Hong, M., Han, G., Zhao, M., Bai, Y., and Chang, S.X.: Grazing intensity affected spatial patterns of vegetation and soil fertility in a desert steppe, Agr. Ecosyst. Environ., 138, 282-292, 2010.

Ma, L., Yuan, F., Liang, H., and Rong, Y.: The effects of grazing management strategies on the vegetation, diet quality, intake and performance of free grazing sheep, Livestock Sci., 161, 185-192, 2014

McNaughton, S. J.: Serengeti grassland ecology: The role of composite environmental factors and contingency in community organization, Ecol. Monogr., 53, 291-320, 1983.

Milchunas, D. G., and Lauenroth, W. K.: Quantitative effects of grazing on vegetation and soils over a global range of environments, Ecol. Monogr., 63, 327-366, 1993.

Oba, G., Vetaas, O. R., and Stenkseth, N. C.: Relationships between biomass and plant species richness in arid-zone grazing lands, $\mathrm{J}$. Appl. Ecol., 38, 836-845, 2001.

Ozgoz, E., Gunal, H., Acir, N., Gokmen, F., Birol, M., and Budak, M.: Soil quality and spatial variability assessment of land use effects in a typic Haplustoll, Land Degrad. Dev., 24, 277-286, 2013

Pellant, M., Shaver, P., Pyke D., and Herrick, J.: Interpreting indicators of rangeland health. Version 3. Technical Reference 1734-1736, available at: ftp://ftp.ftw.nrcs.usda.gov/pub/ glti/IntIndRangeHealth.pdf, 2000.

Peters, D. P. C., Bestelmeyer, B. T., Herrick, J. E., Fredrickson, E. L., Monger, H. C., and Havstad, K. M.: Disentangling complex landscapes: New insights into arid and semiarid system dynamics, BioScience, 56, 491-501, 2006.

Qian, J., Wang, Z., Liu, Z., and Busso, C. A.: Belowground bud bank responses to grazing intensity in the inner-Mongolia steppe, China, Land Degrad. Dev., doi:10.1002/ldr.2300, 2014.

Ren, H., Schönbach, P., Wan, H., Gierus, M., and Taube, F.: Effects of grazing intensity and environmental factors on species composition and diversity in typical steppe of Inner Mongolia, China, PLOS ONE, 7, e52180. doi:10.1371/journal.pone.0052180, 2012.
Rietkerk, M., Ketner, P., Burger, J., Hoorens, B., and Olff, H.: Multiscale soil and vegetation patchiness along a gradient of herbivore impact in a semi-arid grazing system in West Africa, Plant Ecol., 148, 207-224, 2000.

Rossi, R. E., Mulla, D. J., Journel, A. G., and Franz, E. H.: Geostatistical tools for modeling and interpreting ecological spatial dependence, Ecol. Monogr., 62, 277-314, 1992.

Soil Survey Staff: Keys to Soil Taxonomy, 9th Edn., Soil Survey Staff, USDA/NRCS, Washington, DC, 2003.

Schlesinger, W. H., Raikes, J. A., Hartley, A. E., and Cross, A. F.: On the spatial pattern of soil nutrients in desert ecosystems, Ecology, 77, 364-374, 1996.

Schlesinger, W. H., Reynolds, J. F., Cunningham, G. L., Huenneke, L. F., Jarrell, W. M., Virginia, R. A., and Whitford, W. G.: Biological feed backs in global desertification, Science, 247, 10431048, 1990.

Sommer, U.: Benthic microalgal diversity enhanced by spatial heterogeneity of grazing, Oecologia, 122, 284-287, 2000.

Su, Y. Z., Li, L. Y., and Zhao, H. L.: Soil properties and their spatial pattern in a degraded sandy grassland under post-grazing restoration, Inner Mongolia, northern China, Biogeochemistry, 79, 297 314, 2006.

Tongway, D. J. and Ludwig, J. A.: The nature of landscape dysfunction in rangelands, in: Landscape ecology function and management, edited by: Ludwig, J. A., Tongway, D. J., Freudenberger, D., Noble, J., and Hodgkinson, K., CSIRO Publishing: Melbourne, Australia, 48-61, 2003.

Wang, Y. Q. and Shao, M. A.: Spatial variability of soil physical properties in a region of the Loess Plateau of PR China subject to wind and water erosion, Land Degrad. Dev., 24, 296-304, 2013.

Wiesmeier, M., Steffens, M., Kölbl, A., and Kögel-Knabner, I.: Degradation and small-scale spatial homogenization of top soils in intensively-grazed steppes of northern China, Soil Till. Res., 104, 299-310, 2009.

Zhang, X. Y., Sui Y. Y., Zhang, X. D., Meng, K., and Herbert S. J.: Spatial variability of nutrient properties in black soil of northeast China, Pedosphere, 17, 19-29.

Zhao, H. L., Zhao, X., Zhou, R. L., Zhang, T. H., and Drake, S.: Desertification processes due to heavy grazing in sandy rangeland, Inner Mongolia, J. Arid Environ., 62, 309-319, 2005.

Zhao, Y., Peth, S., Hallett, P., Wang, X., Giese, M., and Gao, Y.: Factors controlling the spatial patterns of soil moisture in a grazed semi-arid steppe investigated by multivariate geostatistics, Ecohydrology, 4, 36-48, 2011.

Zhu, L., Johnson, D. A., Wang, W., Ma, L., and Rong Y.: Grazing effects on carbon fluxes in a Northern China grassland, J. Arid Environ., 114, 41-48, 2015. 